\title{
Acknowledgments
}

Special thanks to Stewart Schwab, Laura Cooper, Gregory Crespi, Marc Steinberg, Alan Bromberg, Katherine Van Wezel Stone, and Jennifer Bales for their thoughts and insights on the manuscript; and to Marilyn Mounger and Kathleen Vaughan for their invaluable secretarial assistance.

R. B. 



\section{Compulsory Arbitration}


